\title{
VARIATION ANALYSIS OF DESIGN PARAMETERS OF FIBRE-REINFORCED PLASTIC PARTS
}

\author{
Franz, Michael; Schleich, Benjamin; Wartzack, Sandro \\ Friedrich-Alexander-Universität Erlangen-Nürnberg
}

\begin{abstract}
Lightweight Design as an engineering domain is becoming more and more important in terms of sustainable mobility. Therefore, a large number of researchers is developing methods for utilisation of modern, but as well more complex materials with high lightweight potential. One subgroup of these materials are fibre-reinforced plastics (FRP). A lot of work is done supporting the design engineer in exploiting the structural and mechanical behaviour as good as possible. Whereas variations of laminate parameters, resulting from production, are poorly studied. Their impact especially on defined measures under load is of high importance, e.g. having a look on clearances in automotive industry. Because of the high complexity of FRP-parts, resulting from many laminate parameters, tolerancing is not an intuitive process. This is reflected in the fact that there is no defined procedure for tolerancing of FRPparts. To support the design engineer the authors perform sensitivity analysis for simple loadcases to identify layers with a high importance on a defined measure. The results then are generalised to provide general guidelines to the design engineer.
\end{abstract}

Keywords: Lightweight design, Tolerance representation and management, Uncertainty, Simulation, Fibre reinforced plastics

\section{Contact:}

Franz, Michael

Friedrich-Alexander-Universität Erlangen-Nürnberg

Engineering Design

Germany

franz@mfk.fau.de 


\section{INTRODUCTION AND STATE OF THE ART}

Analysing studies about the potential and growth of lightweight design exposes the importance and future of lightweight design. Lightweight solutions are particularly in demand in the transportation sector (N.N., 2014). On the one hand, lightweight design raises efficiency and therefore saves costs. On the other hand governmental regulations like CO2-reduction (European Union, 2009) focus on sustainability and environmental responsibility, leading to lightweight design as well. Carbon fibre reinforced plastics (CFRP) provide a high lightweight potential. The design of CFRP-parts requires an increased effort, compared to conventional metallic materials. The anisotropic material characteristics must be considered during the design phase, gaining the full lightweight potential (Schürmann, 2007). Therefore, a number of methods, considering the properties of fibre-reinforced plastics during the product development process, emerged. Examples are the topology optimisation algorithms presented by (Völkl et al., 2018) and (Stegmann and Lund, 2005) as well as further approaches for the early development phase which are summarized in (Bruyneel, 2008). Beside methods like presented in (Klein et al., 2015) and (Klein, 2017) which even involve a patch generation, there are also commercial implementations for laminate optimisation (Cervellera et al., 2005).

The named methods result in nominal laminate layouts with, the later they appear in product development process, more detailed designs. Until their implementation into real products, these designs are subject to a multitude of uncertainties and variations from their nominal form, which need to be considered during the design process.

\section{State of the art}

While in (Schleich and Wartzack, 2013) the effect of geometric variations on the structural behaviour was investigated, CFRP-parts need further investigations because of their layerwise ply stack-up. The anisotropic behaviour of CFRP needs to be considered regarding its influence on the structural behaviour and therefore on defined geometric functional measures.

In the field of variation analysis and tolerancing of CFRP parts, with the focus on ply angle variations, different aspects are examined. Conceição and Hoffbauer (Conceição António and Hoffbauer, 2007) concentrate on variations of the angle parameter in a balanced laminate, but not on the influence of independently varying layer angles. In (Jareteg et al., 2014) the aim of the investigations is observing the influence of variations in material properties on the results of a variation analysis with geometric variations. Steinle (Steinle, 2015) in contrast investigates geometric variations resulting from the RTM-process and the laminate parameters. In aeronautical engineering variations of laminate parameters are scrutinized very intensively on CFRP cylinders under buckling load. In (Schillo et al., 2015) the influences of imperfections on the buckling load of unstiffened, wound CFRP cylinders are considered experimentally. They conclude that load imperfections are of much higher importance than geometric imperfections for the buckling load. In (Kepple et al., 2013) furthermore there was found that imperfections of the overall thickness are of high importance beside load imperfections.

Considering modern design tools like the ones resulting in patch reinforced designs as well as upcoming manufacturing processes like Fibre Patch Placement (FPP) further investigations on locally patch reinforced laminate stack-ups have to be performed. The novelty of this work is the investigation of the influence of patch reinforcements on the structural behaviour, compared to a non-reinforced laminate stack-up. Local patch reinforcements lead to asymmetries in the stack-up, which results in couplings. Influences on these couplings are investigated as well. The influences are investigated by sensitivity analysis.

Furthermore trying to avoid computationally intensive sensitivity analysis and to allow the design engineer a good first guess, which layers have a big effect on the structural performance and therefore should be tolerated more strictly, the aim of this work is to find general rules for tolerating CFRP-parts.

\section{PROCEDURES, METHODS AND EXPERIMENTAL SETUP}

In order to find general rules or coherences between model parameters and variations of the part, a method for observing them is needed. To gain information FE-simulation is used because of its easy and fast way to scrutinize different setups. The proceeding used in this paper is presented in Figure 1. In the following section, the most important steps and specialties regarding CFRP are explained.

Because of the high amount of parameters that appear over the product life cycle the first step is to collect as many as possible and sort them in an Ishikawa-diagram. In Figure 2, a selection of factors 
being subject to uncertainties and variations is presented. The factors in the red marked area are typical laminate parameters which might be optimised with the before mentioned design methods. Because of the impact of variating these laminate parameters on the properties and behaviour of the final part there is a need for the application of tolerance management. Tolerance management covers all methods used during the product lifecycle (Stockinger, 2010). According to (Ceglarek and Shi, 1995) it is reasonable to consider tolerances at the earliest possible phase of product development. This can significantly reduce the consequential costs of deviations.

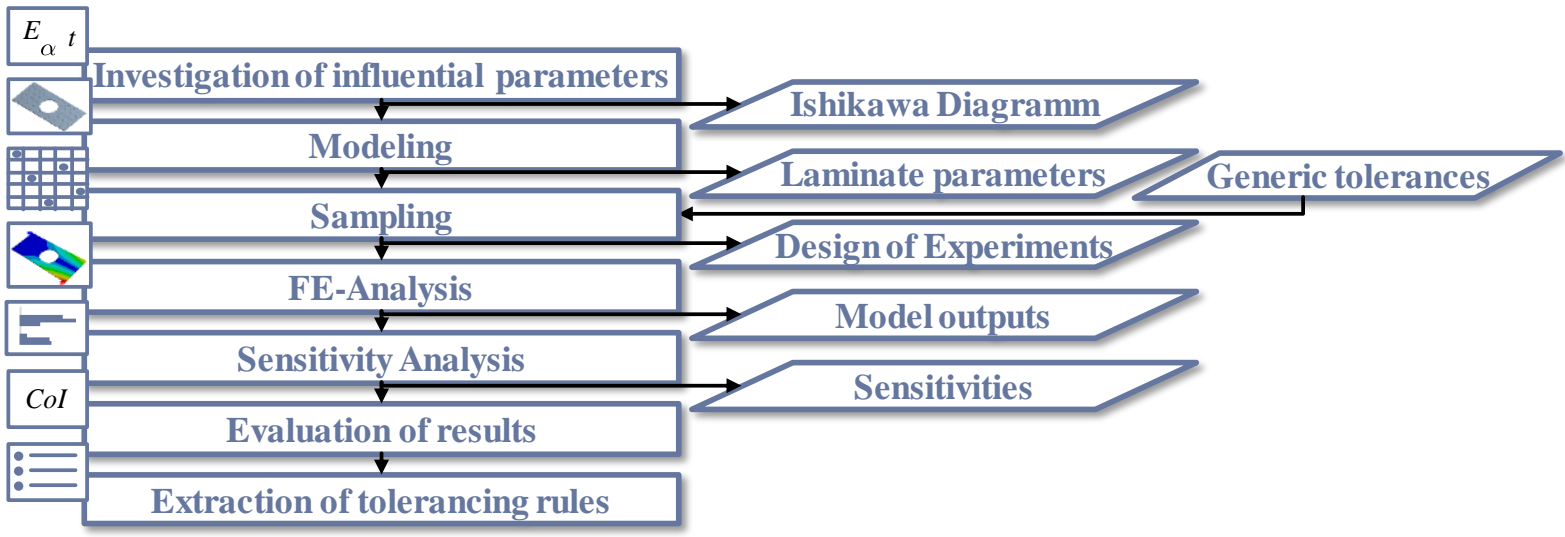

Figure 1: Method for the extraction of tolerancing rules by sensitivity analysis

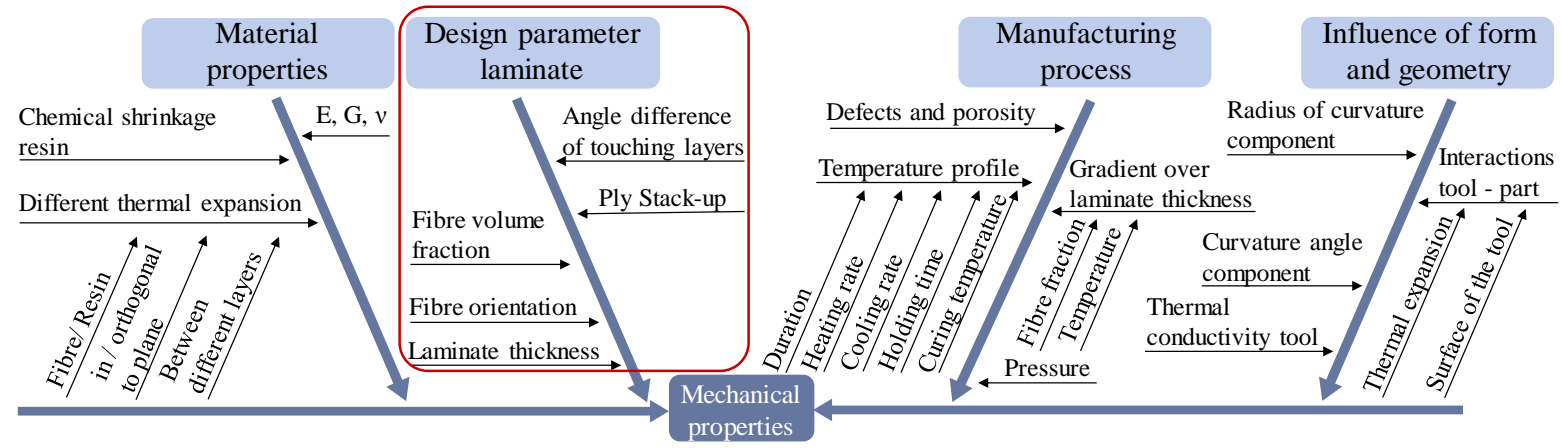

Figure 2: Influencing factors on properties of fibre reinforced plastics based on (Albert, 2002; Dong, 2003, 2010; Svanberg, 2002; Bailie et al., 1997; Sorrentino and Bellini, 2015;

Svanberg and Holmberg, 2001; Walker and Hamilton, 2006; Nielsen, 2013); Red rectangle: laminate parameters which get defined during design phase

\subsection{Finite element-analysis of composite parts}

CFRP-parts reinforced with endless fibres consist of laminates. These are built up by stacking several individual plies. In this paper all plies are considered as unidirectional plies out of continuous fibres. For each ply there are several parameters, which the design engineer needs to define. These parameters, e.g. fibre angle, ply thickness, position and geometry, influence the structural behaviour of the part. For investigation of structural behaviour of parts, the Finite-Element(FE)-Method is a common instrument. For analysing thin CFRP- structures, it is suitable using shell elements. The used eight-node shell element is suitable for layered applications, e.g. composite shells. For the element formulation the first-order shear-deformation theory is assumed. The formulation of laminate stiffness matrix is written as below

$$
\left[\begin{array}{l}
\mathbf{N} \\
\mathbf{M}
\end{array}\right]=\left[\begin{array}{ll}
\mathbf{A} & \mathbf{B} \\
\mathbf{B} & \mathbf{D}
\end{array}\right]\left[\begin{array}{l}
\boldsymbol{\varepsilon} \\
\mathbf{K}
\end{array}\right]
$$

The load vector on the left side consists of the directional forces pooled in $\mathbf{N}$ and the moments pooled in $\mathbf{M}$. On the right side the deformations are combined from the strains $\boldsymbol{\varepsilon}$ and curvatures $\boldsymbol{\kappa}$. The laminate stiffness matrix in the middle consists of the three submatrices $\mathbf{A}, \mathbf{B}$ and $\mathbf{D}$. The matrices $\mathbf{A}, \mathbf{B}$ and $\mathbf{D}$ have the size $[3 \times 3]$. A represents the extensional stiffness matrix, $\mathbf{B}$ the coupling stiffness matrix 
which is zero for symmetric ply stacking and D corresponds to the bending stiffness matrix (Schürmann, 2007; ANSYS Inc., 2017). The three submatrices depend on the material parameters (like the directional Young's moduli, Poisson's ratios and the shear moduli - Figure $3 \mathrm{~b}$ )) as well as on the laminate parameters (like the ply angles and thicknesses). Especially the laminate parameters can lead to asymmetries, which affect the $\mathbf{B}$ matrix and therefore result in couplings. In Figure 3 a) the coupling effects of $\mathbf{B}$, which means a tensional stress can result in a curvature, can be seen.

The realisation of the linear, static FE-Analysis is done within ANSYS 18.2. The modelling of the laminate takes place in the ANSYS ACP-Tool, supporting a layerwise parametric stackup.

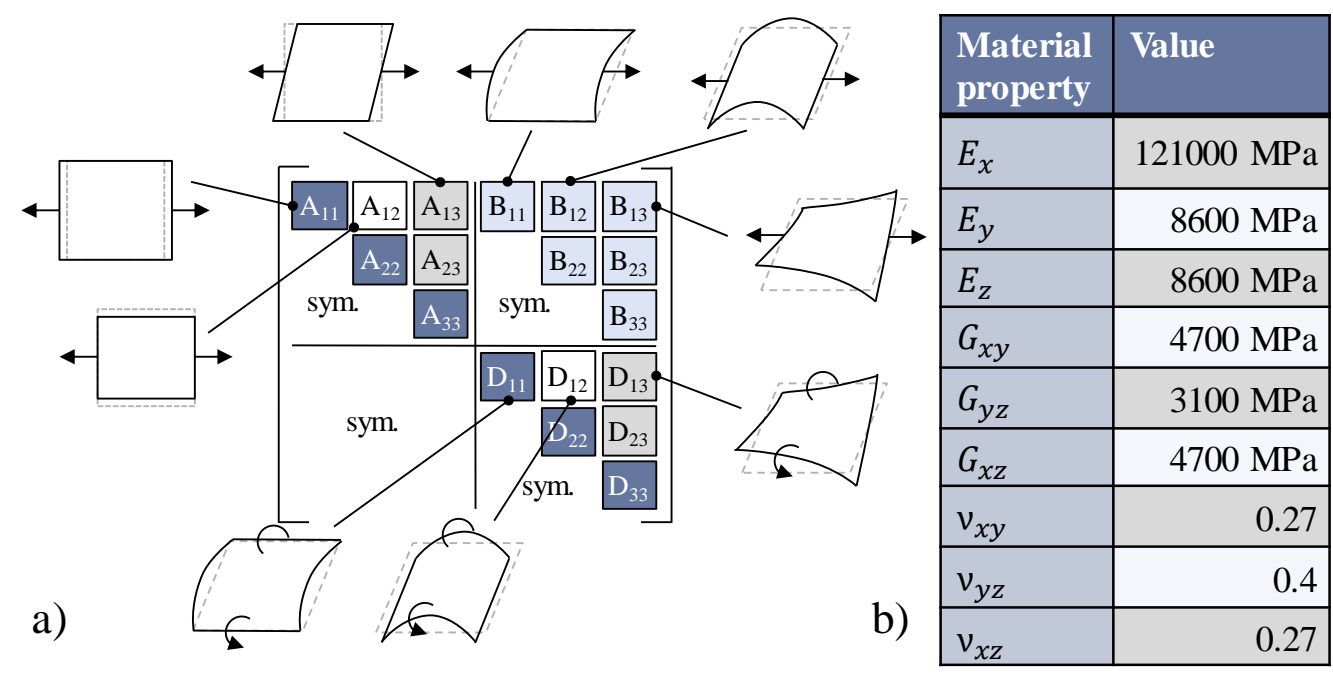

Figure 3: a) Resulting deformations from the entries of the $\boldsymbol{A B D}$-matrix; b) material properties

\subsection{Sensitivity analysis}

To gain information about the behaviour of the part resulting from varying input parameters sensitivity analysis can be used. Sensitivity analysis tries to explain model output variations by the input variations (Saltelli, 2004). The investigations concentrate on the fibre angles as probably being the most important input parameters during the design phase from Figure 2. Because of the highly anisotropic material properties of CFRP, uncertainties in the fibre angles give reason to expect strong coupling effects, which can lead to uncertainties in the model output. The model for the sensitivity analysis consists of the before described FE-method with CFRP material properties (Figure $3 \mathrm{~b}$ ). The model output quantities are geometric quantities, which are defined in chapter 2.3.1.

\subsubsection{Sampling}

The investigation of the influence of input parameters and their uncertainties on the model outputs needs the scanning of the input design space. The input design space results from the use of typical tolerances for the fibre angles of $\pm 5^{\circ}$ to the nominal fibre angle value (Schürmann, 2007). Considering this tolerance value as realisable in production, it limits the design space for each input variable.

For scanning the design space of the variables, a wide variety of methods is available. Sampling methods like the deterministic full factorial sampling or stochastic methods like the random sampling used in Monte Carlo Simulation result in very high sampling sizes (Saltelli, 2004). Trying to reduce the computational effort for solving FE-Analysis, the sampling method Latin Hypercube Sampling (LHS) is chosen. Its aim is to cover the full range of each input variable and at the same time produce robust results even for small samples (Saltelli, 2004). In this paper, a sample size of 500 is used. A uniform distribution of the input variables has to be chosen to gain good information over the whole design space.

\subsubsection{Coefficient of importance}

The aim of the sensitivity analysis is to find the input variables, i.e. ply angles, having a high importance on the output, i.e. geometric quantity, of the FE-Model. Therefore a coefficient first introduced by (Bucher, 2007) is used which later was named as Coefficient of Importance (CoI) and 
was implemented in the commercial software OptiSlang by Dynardo (Most and Will, 2008). The basis of the calculation of the $\mathrm{CoI}$ is a polynomial regression with a quadratic basis

$$
\mathbf{P}^{T} \mathbf{x}=\left[\begin{array}{lllllllll}
1 & x_{1} & x_{2} & \ldots & x_{1}^{2} & x_{2}^{2} & \ldots & x_{1} x_{2} & \ldots
\end{array}\right] .
$$

With a least square fit, the polynomial regression model is adjusted to the calculated data from the FEAnalysis and sampling points. For evaluation of the polynomial regression model, the adjusted Coefficient of Determination (CoD) $R_{a d j}^{2}$ is used.

The CoI calculates the importance of a variable by the difference of the CoD of the complete model and the $\mathrm{CoD}$ of the model reduced by all terms of the observed variable (Most and Will, 2008). The formulation of the CoI can be written like

$$
\mathrm{CoI}_{X_{i}}=R_{a d j, \mathbf{X}}^{2}-R_{a d j, \mathbf{X} \sim i}^{2} .
$$

The CoI varies between zero and one, the more important a variable is, the higher its CoI value will be. The CoI can be seen as an estimate of the total effect sensitivity calculated based on variance (Dynardo $\mathrm{GmbH}, 2017$ ). In this use case an estimation of the sensitivities is good enough for trying to obtain a tendency which input variables are more important than others.

\subsection{Simulative experiments}

In order to gain information about important layer angles of CFRP-parts reinforced with continuous fibres and to later try to generalise them, simulative experiments are executed. These use the presented methods of FE-analysis and sensitivity analysis. The experimental setups are presented in the following regarding the demonstrator, different ply stack-ups and different loadcases.

\subsubsection{Demonstrator}

The selection of a demonstrator for the investigations on the importance of layers resulted in a simple geometry, which is presented in Figure 4. The demonstrator is kept simple to obtain a maximum of information and try to avoid overlaying of different effects on the importance.

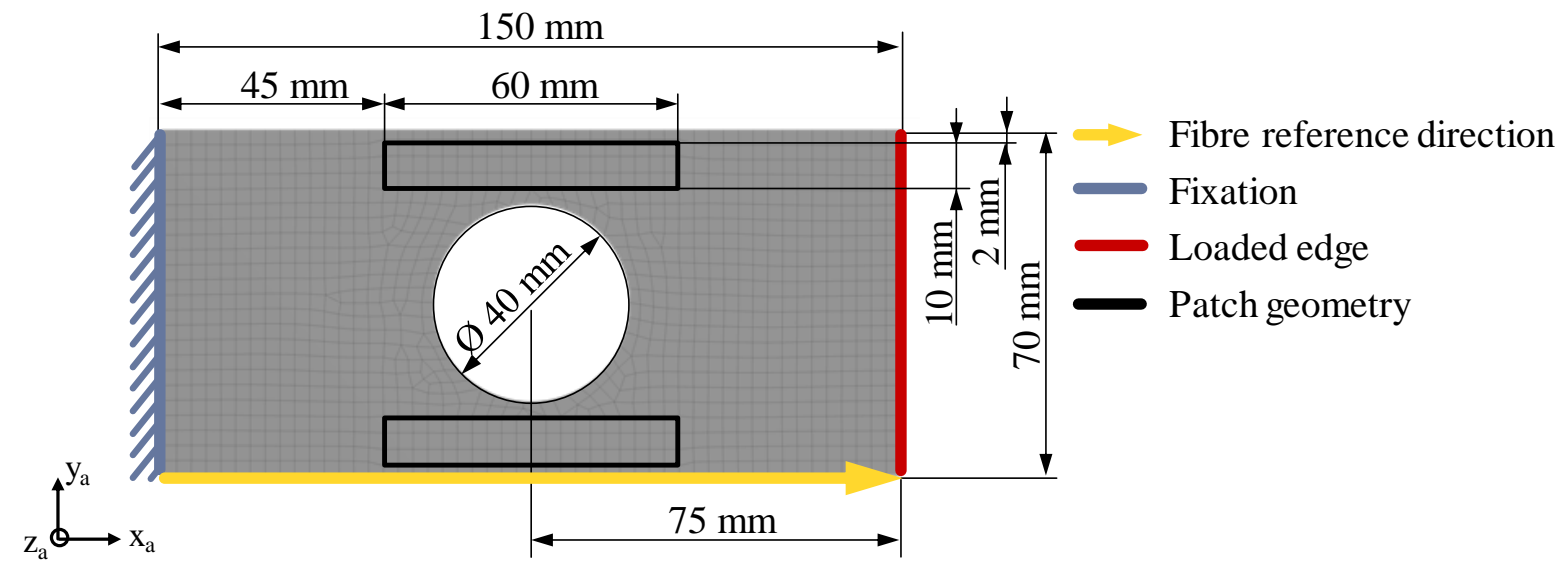

Figure 4: Demonstrators used for sensitivity analysis: plate with a hole

The dimensions of the demonstrator are shown in Figure 4. It is meshed with quad-elements with a maximum size of $3 \mathrm{~mm}$. This results in 1057 elements for the plate demonstrator. At the fixations (blue) all DOFs of the nodes are locked. The red marking shows the edge where the loads are applied depending on the loadcase (see Figure 5). The reference fibre direction, which is needed for the right orientation of the fibres, is marked yellow and defines the $0^{\circ}$ direction. The local patch reinforcements are placed next to the hole in the high stressed areas of the part. In Figure 4 black lines surround the patch areas.

The evaluation of the structural behaviour is done at the loaded edge (red). As results, the mean values of the directional displacements at the edge are investigated. In order to not only recognise uniform displacements of the loaded edge but also check for tilting or curvature of the edge, the standard deviation is calculated. A low standard deviation means low curvature or tilting of the edge, whereas a high standard deviation references to additional deformation to a uniform displacement of the edge. 
Furthermore the investigation of the maximum deformation is considered to result in good information about the behaviour of the part.

\subsubsection{Ply stack-up}

The demonstrator is used in the simulative experiments with two laminate setups. On the one hand the very common quasi isotropic layup $\left(0^{\circ} /+45^{\circ} /-45^{\circ} / 90^{\circ}\right)_{S}$ is used, which is nearly generally applicable and therefore used in a wide variety of parts (Schürmann, 2007). On the other hand, to take the developments regarding lightweight design with local reinforcements into account, the same basic laminate is chosen, but it is reinforced with local patches in the black marked areas. This results in the same laminate layup in the not reinforced areas and to $\left(0^{\circ} /+45^{\circ} /-45^{\circ} / 90^{\circ}\right)_{S}+\left(0^{\circ}\right)_{P a t c h}$ in the reinforced areas, which are shown in Figure 4. The patch is applied in negative z-direction to the plate. The layer height of all plies is set to $0.2 \mathrm{~mm}$.

Using the previously defined design space (chapter 2.2.1) and the ply stack-up, the following parameter ranges result for the layer angles. The non-reinforced ply stack-up varies between $\left(-5^{\circ} \ldots+5^{\circ} / 40^{\circ} \ldots 50^{\circ} /-50^{\circ} \ldots-40^{\circ} / 85^{\circ} \ldots 95^{\circ} / 85^{\circ} \ldots 95^{\circ} /-50^{\circ} \ldots-40^{\circ} / 40^{\circ} \ldots 50^{\circ} /-5^{\circ} \ldots 5^{\circ}\right)$. The patch reinforced ply stack-up varies in the ranges of:

$\left(-5^{\circ} \ldots+5^{\circ} / 40^{\circ} \ldots 50^{\circ} /-50^{\circ} \ldots-40^{\circ} / 85^{\circ} \ldots 95^{\circ} / 85^{\circ} \ldots 95^{\circ} /-50^{\circ} \ldots-40^{\circ} / 40^{\circ} \ldots 50^{\circ} /-5^{\circ} \ldots 5^{\circ}\right)+$ $\left(-5^{\circ} \ldots 5^{\circ}\right)_{\text {Patch }}$.

\subsubsection{Loadcases}

Testing the sensitivities of the demonstrator is done for different simple loadcases, which are presented in Figure 5 for the plate demonstrator. The loadcases can't reflect the manifold and complexity of real applications and their loadcases but tries to cover the most general loadcases that can occur.

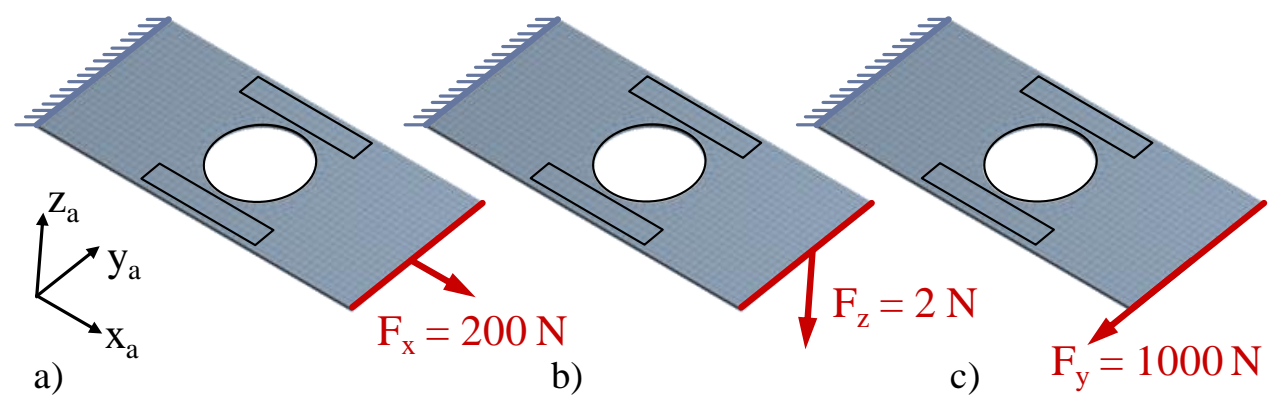

Figure 5: Loadcases for the plate demonstrator and the applied forces

\section{RESULTS}

With the given demonstrator, ply stack-ups and loadcases multiple sensitivity analysis are performed using the CoI as sensitivity value. The samples of the Design of Experiments (DoE), which is needed for the realisation of the simulative experiments, are generated by the presented LHS method. Using the model outputs, i.e. the mean displacements at the loaded edge and the standard deviations of the displacements of the edge, the importance values of the single layers on the model outputs are calculated and presented in the following. Depending on the loadcase and the deformations with nominal ply angles a preselection of the results has been performed.

\subsection{Loadcase tension}

The results of the plate demonstrator for the tension loadcase are presented in Figure 6. The two colours show the CoI values for the ply stack-up with patches (dark blue) and without patches (light blue). There are no significant differences between the two ply stack-ups. Though the patches cause the couplings in the part, the patches have no influence on the variation of the deformations. Compared to the other layers the patches are not important on changes of the deformation in load direction or cross to it. Whereas the layers with $\pm 45^{\circ}$ fibre angles have a high importance for the mean displacement in $\mathrm{x}$ - and z-direction. For the x-direction the importance can be explained by high stiffness gains and losses with change of the fibre angle, while resulting asymmetries can lead to a displacement in z-direction. The higher the 
distance to the midplane is, the higher the importance gets. Furthermore the $0^{\circ}$-layers have a high importance on the tilting and warping of the loaded edge, which can be seen in Figure $6 \mathrm{~d}$ ). Looking at the layer importance regarding the maximum deformation, it can be seen that the outer layers have a higher importance indicating on tilting and warping.

Summarising the tension loadcase, the further out the position of the layer is, the higher is its importance and the need for tighter tolerances, to avoid displacement out of the load direction as well as tilting and warpage. Variation of the $\pm 45^{\circ}$-layers furthermore effects the deformation in load direction. However, the patches have no influence on this loadcase and demonstrator.

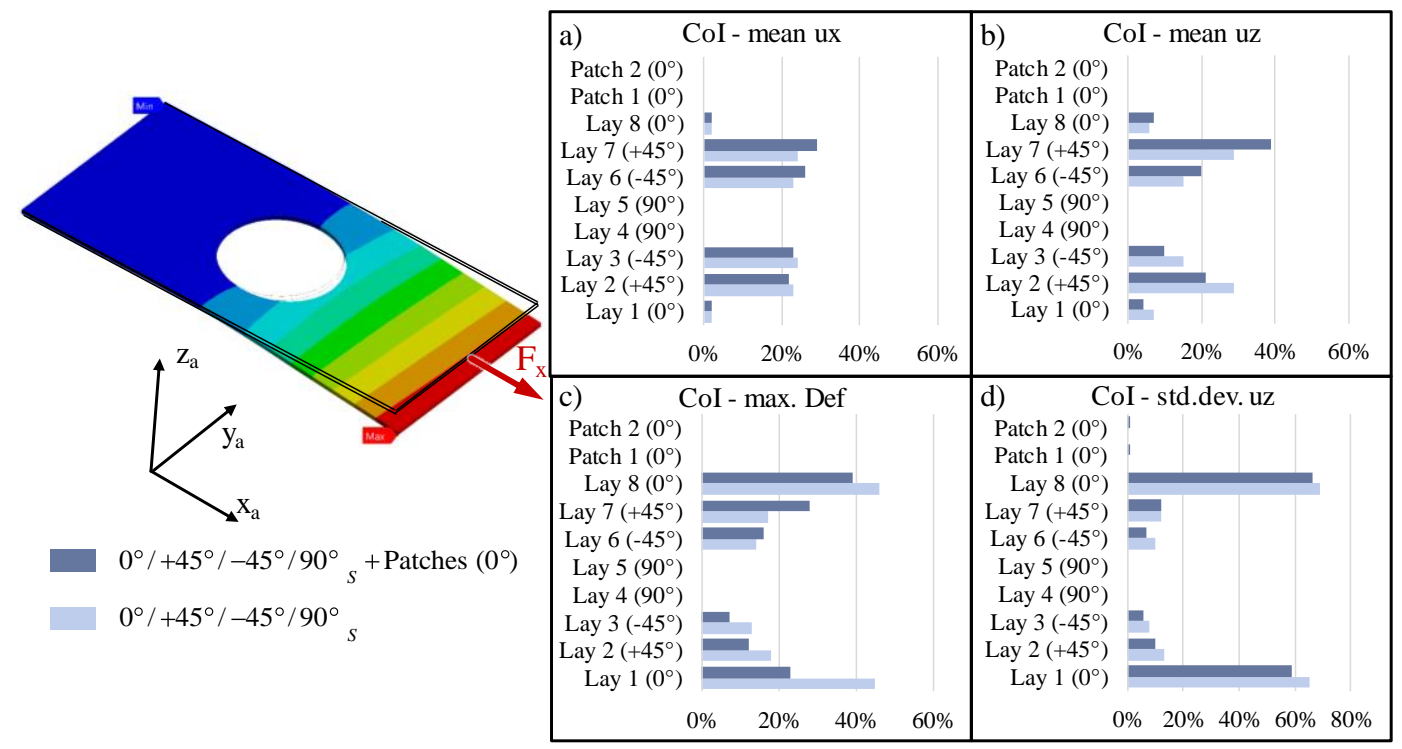

Figure 6: Deformed part with patched nominal ply stack-up under tensional loading (left); Coefficients of Importance of the layer angles on a) mean displacement in $x$-direction,

b) mean displacement in z-direction, c) maximum deformation and d) standard deviation of displacement in z-direction

\subsection{Loadcase bending}

The results of the first bending loadcase in Figure 7 show no importance of the patch angles, like in the tension loadcase. This may be explained by smaller changes in the stiffness matrix through variations of the patches compared to variations in the main laminate. The results of the ply stack-ups differ only slightly from each other.
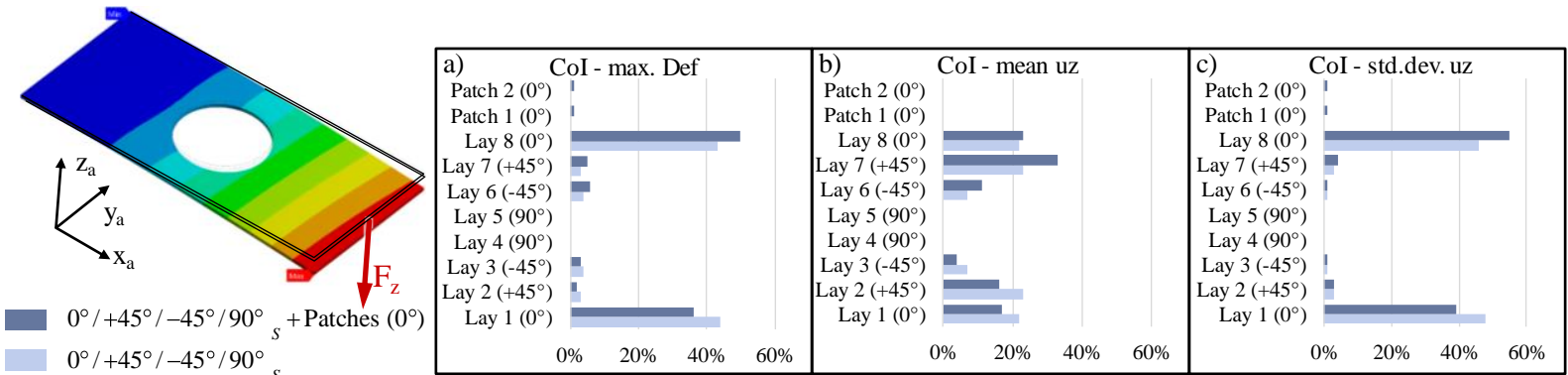

Figure 7: Deformed part with patched nominal ply stack-up under bending load (left); Coefficients of Importance of the layer angles on a) maximum deformation, b) mean displacement in z-direction and c) standard deviation of displacement in z-direction

The small differences can be explained by a displacement of the midplane what results in asymmetric distances of the corresponding layers to the midplane. Nonetheless the important layers stay the same. The outer layers have a higher importance on the mean displacement in z-direction presented in Figure 7b). The $45^{\circ}$ layers are of higher importance according to the high losses or gains in stiffness with variation of the angle, while the $0^{\circ}$-layers are of very high importance to the standard deviation in z-direction and the maximum deformation. Like in the tension loadcase, the $0^{\circ}$-layers are important for the tilting and the warpage of the edge. Tighter tolerances of the $0^{\circ}$-layers would therefore reduce the variation of the tilting, while tighter tolerances of the $45^{\circ}$-layers reduce the variation in the mean displacement. 
The results of the second bending loadcase are presented in Figure 8. The mean displacement in ydirection is the mainly expected deformation. The CoI values show, that the load carrying layers with $45^{\circ}$ fibre angle have a high importance on the expected deformation. The displacement of the part out of its plane, which results from the couplings, is affected by the variation of the $0^{\circ}$-layers. The $45^{\circ}$ layers are of high importance on the standard deviations in the part-plane directions, which can be argued as well with them being the load carrying layers. For the standard deviation of the zdisplacements, the patches are important for the first time. Beside the patches, the $0^{\circ}$ - and $-45^{\circ}$-layers are important. In this loadcase the results of the different stack-ups differ about $10 \%$. To sum up by looking at the maximum deformation, the $0^{\circ}$-layers are of high importance and the $\pm 45^{\circ}$ layers low importance. The $\pm 45^{\circ}$-layers mainly affect the variations in the part-plane because of carrying the loads, whereas the $0^{\circ}$-layers generate asymmetries. The influence of patch angle variations on the maximum deformation is, despite its importance on the tilting and warping in z-direction, very low.

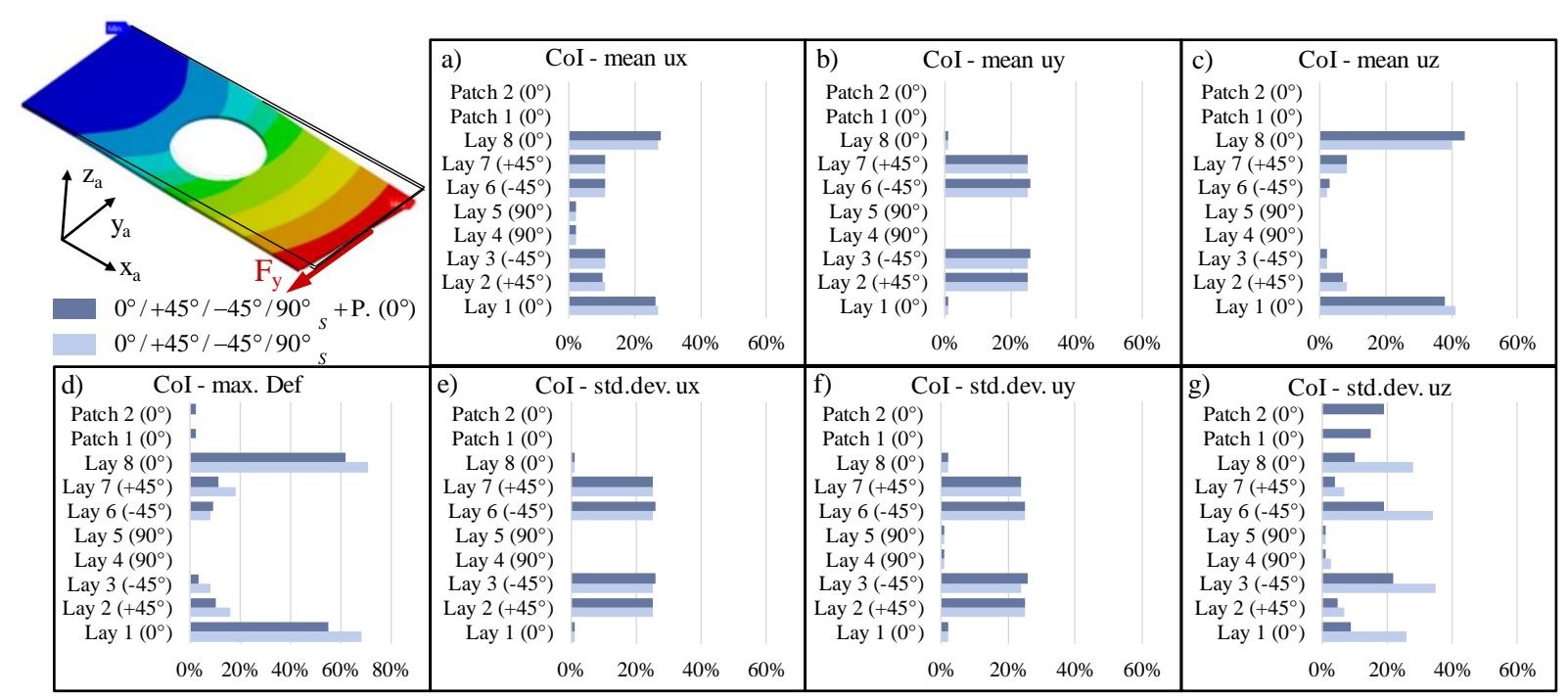

Figure 8: Deformed part with patched nominal ply stack-up under bending load (left); Coefficients of Importance of the layer angles on a) mean displacement in $x$-direction, b) mean displacement in $y$-direction, c) mean displacement in y-direction, d) maximum deformation, e) standard deviation of displacement in $x$-direction, $f$ ) standard deviation of displacement in $y$-direction, g) standard deviation of displacement in $z$-direction

\section{DISCUSSION AND CONCLUSION - DEDUCTION OF GUIDELINES FOR TOLERANCING CFRP PARTS}

Concluding the results of the performed sensitivity analyses, there are three subjects, which need to be considered while adapting tolerances of fibre reinforced parts. The three subjects are the loadcase, the ply stack-up and the fibre angle of the layer. Considering the loadcase is needed because of different resulting effects, coming for example from the direction of bending and the possible coupling effects. In most cases the layers with fibre angles in load direction effect tilting and warpage.

The second subject, considering the ply stack-up, is relevant in all bending loadcases or bending effects for example resulting from the couplings. The outer layers are of higher importance due to their higher area moment of inertia. The third subject, the layer fibre angle, addresses whether a variation of the fibre angle leads to high stiffness changes in the layer because of the anisotropic behaviour. For example variations of the $45^{\circ}$-layers in the tension loadcase lead to high changes in the stiffness and therefore are important on the displacement in load direction.

A first approach to generalize this knowledge and to make it applicable to parts that are more complex can be found in Figure 9. Its aim is to adjust fibre angle tolerances based on the structural behaviour. In the first step the different loadstates occurring in the part have to be identified. For example the evaluation of shell stresses in thickness direction of the shell element can show areas under bending (tension - pressure) or tension. The intensity can be taken as an indicator of the importance of this area. In the following steps the ply stack-ups and orientations in these areas have to be identified and then compared to the loadstates and their directions. For the different possible loads a differentiation 
has to be done, to detect the important layers for each area. With the knowledge gained through the sensitivity analyses, the tolerances of the important layers can then be adjusted.

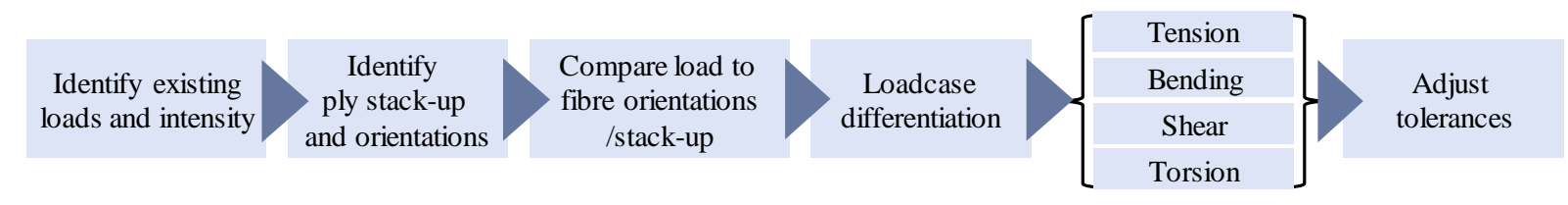

Figure 9: Method for adjusting fibre angle tolerances in fibre reinforced plastic parts

A further observed aspect is the influence of reinforcing patches. The presence of additional patches can positively affect the structural performance but as well lead to asymmetries and therefore undesired deformations. Though the patch reinforcements cause significant coupling deformations the variation of their fibre angles in contrast are hardly relevant for the variations of the model outputs. This is explained by the low proportion on the stiffness compared to the other layers. Therefore, further investigations of structures with a higher amount of reinforcing patches are needed.

The presented work shows the need for research on the topic of effects resulting from variations in CFRP-parts, especially locally reinforced parts. Based on a study of influential parameters, the fibre angle was chosen for further investigations of its influence in different loadcases and ply stack-ups. The results showed that the important layer angles are depending on the loadcase, the stack-up and the fibre angle itself. With these three subjects in mind, the design engineer can do adaption of the tolerances of influential layer angles based on engineering knowledge and avoid computationally expensive sensitivity analysis. Nonetheless further research is needed. On the one hand, the experiments need to be extended to geometries with more complex shapes and a higher amount of patch reinforcements. On the other hand, further parameters like the layer thicknesses need to be observed.

\section{REFERENCES}

Albert, C. (2002), "Spring-in and warpage of angled composite laminates", Composites Science and Technology, Vol. 62 No. 14, pp. 1895-1912.

ANSYS Inc. (2017), ANSYS Help: ANSYS Dokumentation, SAS IP Inc., Canonsburg, PA 15317.

Bailie, J.A., Ley, R.P. and Pasricha, A. (1997), "A summary and review of composite laminate design guidelines", Task 22 NASA Contract NAS1-19347. Military aircraft Systems Division, El Segundo, CA.

Bruyneel, M. (2008), "Optimization of laminated composite structures: problems, solution procedures and applications”, In: Durand, L.P. (Ed.), Composite Materials Research Progress, NOVA Science Publishers.

Bucher, C. (2007), "Basic concepts for robustness evaluation using stochastic analysis", Paper Presented at EUROMECH Colloquium 482, 10.-12.09.2007, London, available at: https://www.dynardo.de/fileadmin/Material_Dynardo/bibliothek/Robustheit_Zuverlaessigkeit/Paper_Buch er.pdf (accessed 31 October 2018).

Ceglarek, D. and Shi, J. (1995), "Dimensional variation reduction for automotive body assembly", Manufacturing Review, Vol. 8 No. 2.

Cervellera, P., Zhou, M. and Schramm, U. (2005), "Optimization driven design of shell structures under stiffness, strength and stability requirements", In: Herskovits, J., Mazorche, S. and Canelas, A. (Eds.), WCSMO6: 6th World Congress on Structural and Multidisciplinary Optimization, 30th May to 3rd June 2005, Rio de Janeiro, Brazil Book of Abstracts and CD-ROM Proceedings, COPPE Publication, Rio de Janeiro, Brazil.

Conceição António, C. and Hoffbauer, L.N. (2007), "Uncertainty analysis based on sensitivity applied to angleply composite structures”, Reliability Engineering \& System Safety, Vol. 92 No. 10, pp. 1353-1362.

Dong, C. (2003), Dimension Variation Prediction and Control for Composites, Dissertation, Florida State University.

Dong, C. (2010), "A parametric study on the process-induced deformation of composite T-stiffener structures", Composites Part A: Applied Science and Manufacturing, Vol. 41 No. 4, pp. 515-520.

Dynardo GmbH (2017), Methods for Multi-Disciplinary Optimization and Roboustness Analysis, Weimar.

European Union (2009), Regulation (EC) No 443/2009 of the European Parliament and of the Council of 23 April 2009 Setting Emission Performance Standards for New Passenger Cars as Part of the Community's Integrated Approach to Reduce CO 2 Emissions from Light-Duty Vehicles: OJ L 140.

Jareteg, C., Wärmefjord, K., Söderberg, R., Lindkvist, L., Carlson, J., Cromvik, C. and Edelvik, F. (2014), "Variation simulation for composite parts and assemblies including variation in fiber orientation and thickness", Procedia CIRP, Vol. 23, pp. 235-240. 
Kepple, J., Prusty, B.G., Pearce, G., Kelly, D., Thomson, R. and Degenhardt, R. (2013), "INFLUENCE OF IMPERFECTIONS ON AXIAL BUCKLING LOAD OF COMPOSITE CYLINDRICAL SHELLS”, In: Hoa, S.V. and Hubert, P. (Eds.), International Conference on Composite Materials 2013 (ICCM-19): Montreal, Quebec, Canada, 28 July - 2 August 2013, Curran Associates, Inc, Red Hook, NY, pp. 5332-5341.

Klein, D. (2017), "Ein simulationsbasierter Ansatz für die beanspruchungsgerechte Auslegung endlosfaserverstärkter Faserverbundstrukturen”, Dissertation, Friedrich-Alexander-Universität ErlangenNürnberg, 2017.

Klein, D., Malezki, W. and Wartzack, S. (2015), "Introduction of a computational approach for the design of composite structures at the early embodiment design stage", In: Weber, C., Husung, S., Cantamessa, M., Cascini, G., Marjanovic, D. and Graziosi, S. (Eds.), Design for life: The 20th International Conference on Engineering Design (ICED 15); 27th - 30th July 2015, Politecnico di Milano, Italy, Design Society, Glasgow, pp. 105-114.

Most, T. and Will, J. (2008), "Meta-model of Optimal Prognosisi - An automatic approach for variable reduction and optimal meta-model selection", Paper Presented at Weimarer Optimierungs- und Stochastiktage 5.0, 20.-21.11.2008, Weimar, available at:

https://www.dynardo.de/fileadmin/Material_Dynardo/WOST/Paper/wost5.0/Paper_Most.pdf (accessed 31 October 2018).

N.N. (2014), Leichtbau - Trends und Zukunftsmärkte: und deren Bedeutung für Baden-Württemberg, available at: http://www.leichtbaubw.de/fileadmin/user_upload/PDF/RZ_LeichtbauBW_Studie_Trends_Zukunftsmaerkte_Web.pdf (accessed 20 June 2017).

Nielsen, M.W. (2013), "Prediction of process induced shape distortions and residual stresses in large fibre reinforced composite laminates: With application to Wind Turbine Blades”, Technical University of Denmark (DTU), Kgs. Lyngby, 2013.

Saltelli, A. (Ed.) (2004), Sensitivity Analysis, Wiley Series in Probability and Statistics, Reprinted., Wiley, Chichester.

Schillo, C., Röstermundt, D. and Krause, D. (2015), "Experimental and numerical study on the influence of imperfections on the buckling load of unstiffened CFRP shells”, Composite Structures, Vol. 131, pp. 128-138.

Schleich, B. and Wartzack, S. (2013), "How to determine the influence of geometric deviations on elastic deformations and the structural performance?", Proceedings of the Institution of Mechanical Engineers, Part B: Journal of Engineering Manufacture, Vol. 227 No. 5, pp. 754-764.

Schürmann, H. (2007), Konstruieren mit Faser-Kunststoff-Verbunden, 2nd ed., Springer, Berlin, Heidelberg.

Sorrentino, L. and Bellini, C. (2015), "Compaction influence on spring-in of thin composite parts. Experimental and numerical results”, Journal of Composite Materials, Vol. 49 No. 17, pp. 2149-2158.

Stegmann, J. and Lund, E. (2005), "Discrete material optimization of general composite shell structures", International Journal for Numerical Methods in Engineering, Vol. 62 No. 14, pp. 2009-2027.

Steinle, P. (2015), “Toleranzmanagement für Bauteile aus kohlenstofffaserverstärktem Kunststoff - Ursachen der geometrischen Streuung, präventive Vorhersagen der Maßhaltigkeit und der Einsatz des Werkstoffes im Rohbau", available at: https://publikationen.bibliothek.kit.edu/1000047236 (accessed 1 December 2016).

Stockinger, A. (2010), “Computer Aided Robust Design - Verknüpfung rechnerunterstützter Entwicklung und virtueller Fertigung als Baustein des Toleranzmanagements”, Dissertation, Friedrich-AlexanderUniversität Erlangen-Nürnberg (FAU), Erlangen, 2010.

Svanberg, J.M. (2002), Predictions of Manufacturing Induced Shape Distortions - High Performance Thermoset Composites, Dissertation, Luleå University of Technology.

Svanberg, J.M. and Holmberg, J.A. (2001), "An experimental investigation on mechanisms for manufacturing induced shape distortions in homogeneous and balanced laminates", Composites Part A: Applied Science and Manufacturing, Vol. 32 No. 6, pp. 827-838.

Völkl, H., Klein, D., Franz, M. and Wartzack, S. (2018), “An efficient bionic topology optimization method for transversely isotropic materials", Composite Structures.

Walker, M. and Hamilton, R. (2006), "A technique for optimally designing fibre-reinforced laminated plates under in-plane loads for minimum weight with manufacturing uncertainties accounted for", Engineering with Computers, Vol. 21 No. 4, pp. 282-288.

\section{ACKNOWLEDGMENTS}

The authors thank the German Research Foundation (DFG) for funding the research project WA 2913/29-1

"Tolerancing during the design of endless-fiber reinforced composite structures" 